\title{
Hot Deformation Behavior and Microstructure Evolution of 2219/TiB 2 Al-matrix Composite
}

\author{
Wang Jing ${ }^{a, b *} \mathbb{1}$, Liang Qiang ${ }^{a, b}$, Li Ping ${ }^{a, b}$ \\ ${ }^{a}$ Chongqing Technology and Business University, School of Mechanical Engineering, Chongqing, \\ 400067, China \\ ${ }^{b}$ Design and Control Key Laboratory of Manufacturing Equipment Mechanism of Chongqing, \\ Chongqing, 400067, China
}

Received: January 8, 2020; Revised: March 26, 2020; Accepted: March 27, 2020

\begin{abstract}
Hot compression tests for 2219/TiB ${ }_{2}$ Al-matrix composite were conducted on a Gleeble-3500 isothermal simulator in the temperature range of $300 \sim 500^{\circ} \mathrm{C}$ and strain rates of $0.01,0.1,1,10 \mathrm{~s}^{-1}$ to obtain true stress strain curves. The original Johnson-Cook model was calculated and used to describe the constitutive relationship of hot deformation behavior of this composite. After precision evaluation and analysis, a new modified Johnson-Cook model was proposed. Comparing with the original model, the new model has a lower absolute average relative error (AARE) of $6.4415 \%$ and a higher relative error (R) of 0.9852 , which indicates better prediction precision. Meanwhile, to understand the intrinsic workability of this composite, processing map based on dynamic materials model was constructed. Two stable regions locating at $300 \sim 400^{\circ} \mathrm{C} \& 0.01 \sim 0.1 \mathrm{~s}^{-1}$ and $420 \sim 500^{\circ} \mathrm{C} \& 0.01 \sim 1 \mathrm{~s}^{-1}$ were identified by the processing map and the instable microstructure in the instability region validated the reliability of the processing map. Furthermore, the microstructure evolution was analyzed and the results revealed that the $\theta$-phase reduced with the increasing temperature.
\end{abstract}

Keywords: 2219/TiB ${ }_{2}$ Al-matrix composite; modified Johnson-Cook model; processing map; microstructure evolution.

\section{Introduction}

Aluminum matrix composites (AMCs) are increasingly used in aerospace, aircraft, automotive industries due to the advantages such as light weight, good wear resistance, high specific strength and low thermal expansion coefficient ${ }^{1-3}$. So far, the main widely used reinforcing particles for AMCs are $\mathrm{Ni}_{2} \mathrm{O}_{3}{ }^{4}, \mathrm{Al}_{2} \mathrm{O}_{3}{ }^{3}, \mathrm{ZrB}_{2}{ }^{5}, \mathrm{SiC}^{1,6}$ and $\mathrm{TiB}_{2}{ }^{7}$ etc. Among these strengthened $\mathrm{Al}$-matrix composites, the main research goals of previous research reports were at obtaining good adhesion property at the interface of particles and matrix and mature fabrication processes. However, the hot deformation behavior of the composites was few reported.

Hot deformation behaviors of alloys were normally studied using constitutive models and processing maps ${ }^{8-10}$. Until now, many constitutive models to describe the hot flow behaviors of alloys were developed. As early as in 1966, C.M. Sellars and W.J. McTegart proposed the nowadays most widely used Arrhenius model. Subsequently, G.R. Johnson and W.H. Cook firstly proposed the Johnson-Cook model for describing severe plastic deformation behavior of metal in $1983^{11}$ and F.J. Zerilli and R.W. Armstrong proposed the Zerilli-Armstrong model based on dislocation mechanics in $1986^{12}$. As one of the most classical phenomenological models, Johnson-Cook model has been widely used due to its comprehensive advantages of simplicity and high precision ${ }^{13-15}$. Nevertheless, the original Johnson-Cook model cannot describe the flow behavior of most alloys with high precision and researchers normally like to modify the model to better suit the flow behavior of

*e-mail: ctbuwangjing@163.com a certain alloy ${ }^{15-17}$. Hence, it is possible to develop a better modified Johnson-Cook model for 2219/ $\mathrm{TiB}_{2}$ Al-matrix composite since this field has been rarely reported. Meanwhile, processing map has become a mature method to identify the intrinsic workability of alloys ${ }^{18-21}$, but it was either seldom used in the investigations of $2219 / \mathrm{TiB}_{2} \mathrm{Al}$-matrix composite. To better understand the hot deformation behavior and intrinsic workability of $2219 / \mathrm{TiB}_{2} \mathrm{Al}$-matrix composite, it is important to construct the suitable constitutive model and processing map for it. Besides, investigating the effect of ceramic particles in the microstructure evolution during hot deformation of $2219 / \mathrm{TiB}_{2} \mathrm{Al}$-matrix composite is also necessary.

In this study, the original Johnson-Cook constitutive model for 2219/TiB 2 Al-matrix composite was firstly constructed and the prediction precision was evaluated. After analyzing the main factors limiting the precision of the model, a modified Johnson-Cook model was proposed to better describing the flow behavior of this composite. Meanwhile, the processing map at the strain of 0.9 was developed to identify the intrinsic workability of this composite. Subsequently, the microstructure evolution was analyzed by optical microscopy and used to verify the processing map, at the same time, the microstructure evolution during hot deformation was studied.

\section{Experimental}

The as-received material is a homogenized ingot $2219 / \mathrm{TiB}_{2}$ Al-matrix composite with chemical compositions (wt. $\%$ ) of $5.8-6.8 \mathrm{Cu}, 0.2-0.4 \mathrm{Mn}, 0.2 \mathrm{Si}$, 
$0.1-0.25 \mathrm{Zr}, 0.3 \mathrm{Fe}, 0.02 \mathrm{Mg}, 0.1 \mathrm{Zn}, 0.02-0.1 \mathrm{~V}$, balance $\mathrm{Al}$, and the addition of $6 \mathrm{vol} . \% \mathrm{TiB}_{2}$ particles. The optical microscopy (OM) and scanning electronic microscopy (SEM) microstructures of the alloy under as-received condition are shown in Figure 1a and 1b. Also, the EDS mapping of B and Ti elements are shown in Figure 1c and 1d. To prepare for hot compression tests, the specimens were cut into cuboid with dimensions of $10 \mathrm{~mm} \times 15 \mathrm{~mm} \times 20 \mathrm{~mm}$. Hot compression tests were conducted on a Gleeble-3500 isothermal simulator at the temperature range of $300 \sim 500^{\circ} \mathrm{C}$ with an interval of $50^{\circ} \mathrm{C}$ and the strain rate range of $0.01 \sim 10 \mathrm{~s}^{-1}$ and the height reduction of $60 \%$. To reduce the effect of friction, graphite flakes were added between the anvils and the largest end faces of specimens. Also, to ensure uniformed temperature distribution before compressing, specimens were heated by $10^{\circ} \mathrm{C} / \mathrm{s}$ to a certain temperature and held $180 \mathrm{~s}$. The nominal stress strain data were automatically obtained by a computerassisted monitor and interpreted into true stress strain data.

\section{Results and Discussion}

\subsection{True stress strain curves}

Figure 2 shows the measured true stress strain curves of $2219 / \mathrm{TiB}_{2} \mathrm{Al}$-matrix composite at different conditions. It can be seen that true stress varies with the deformation temperature and strain rate distinctly. Higher deformation

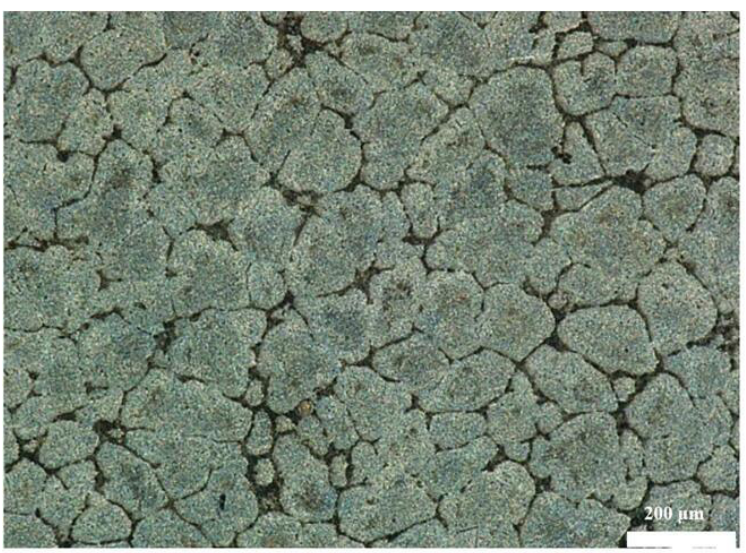

(a)

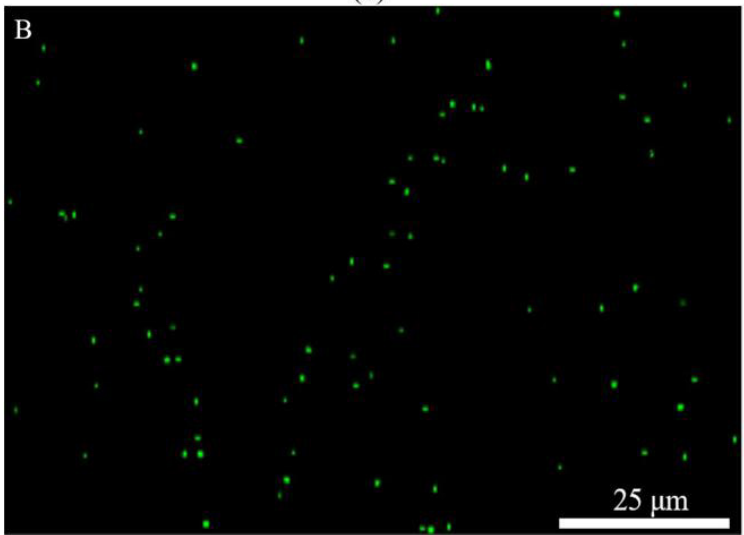

(c) temperature and lower strain rate will result in lower true stress, a conventional explain for this phenomenon is that the nucleation of dynamic recrystallization is easier to process under higher temperature and lower strain rate r2-24. $^{2}$. Besides, the true stress increases dramatically at the initial stage of deformation and decreases with the increasing strain, which is caused by the predomination of work hardening at the beginning of deformation and the subsequent effect of dynamic recovery and dynamic recrystallization becoming stronger with the increasing strain.

\subsection{Construction of Johnson-Cook model}

As an empirical model, Johnson-Cook constitutive model was firstly proposed by Gordon R. Johnson and William H. Cook in 1983 to describe the relationship between flow stress and deformation parameters including strain, strain rate and temperature for the large plastic deformation of alloys ${ }^{11}$. It was expressed as following:

$$
\sigma=\left(A+B \varepsilon^{n}\right)\left[1+C \ln \left(\dot{\varepsilon}^{*}\right)\right]\left[1-\left(\frac{T-T_{r e f}}{T_{m}-T_{r e f}}\right)^{m}\right]
$$

where $\sigma, \varepsilon$ are the flow stress, strain, $\dot{\varepsilon}^{*}=\dot{\varepsilon} / \dot{\varepsilon}_{r e f}, \dot{\varepsilon}$ is the strain rate, $\dot{\varepsilon}_{r e f}$ is the reference strain rate, $T$ is the current absolute temperature, $T_{m}$ is the melting temperature, here, $T_{m}=650^{\circ} \mathrm{C}$, $T_{r e f}$ is the reference temperature, respectively. $A$ is the yielding

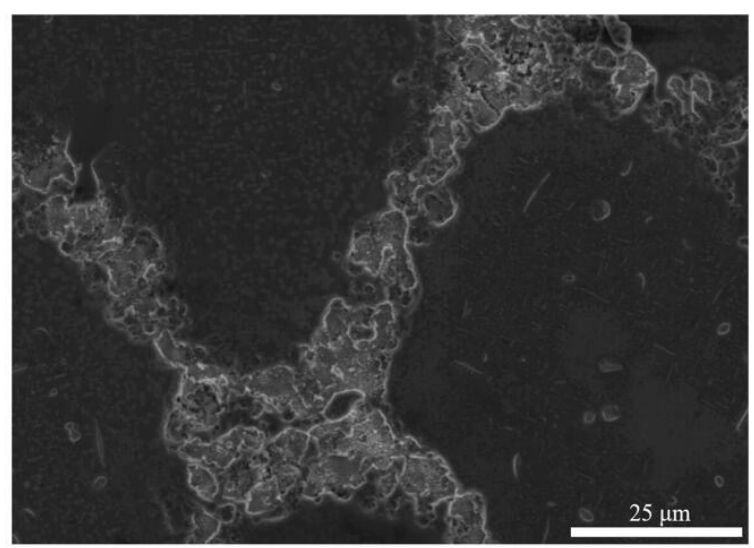

(b)

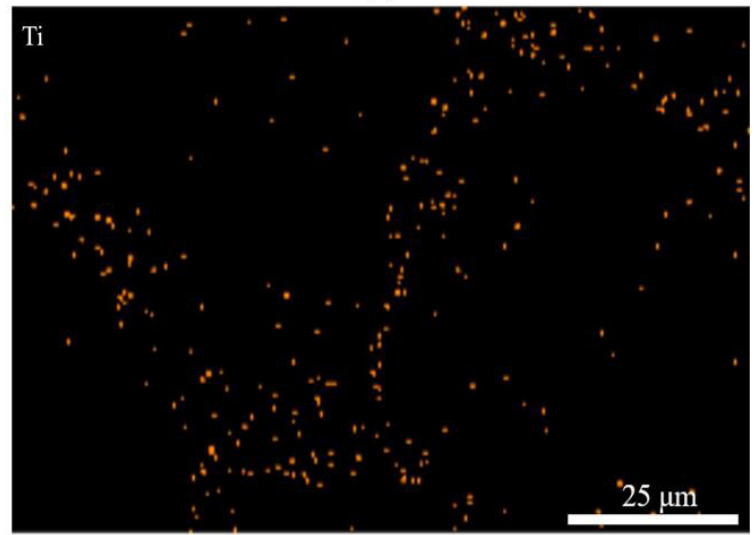

(d)

Figure 1. (a) the OM microstructure; (b) the SEM microstructure; the EDS mapping of (c) B and (d) Ti elements. 


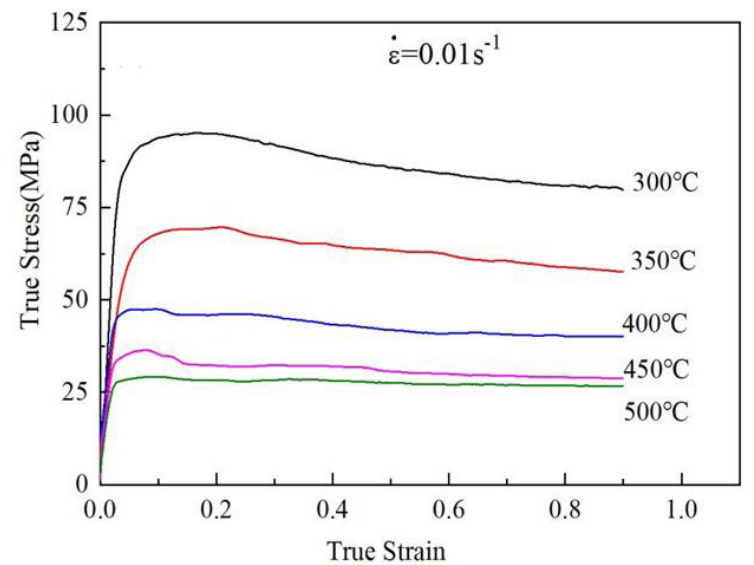

(a)

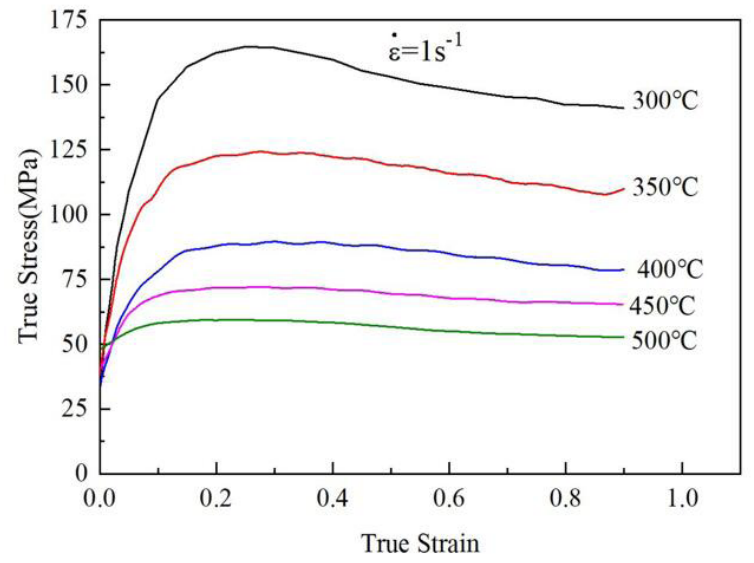

(c)

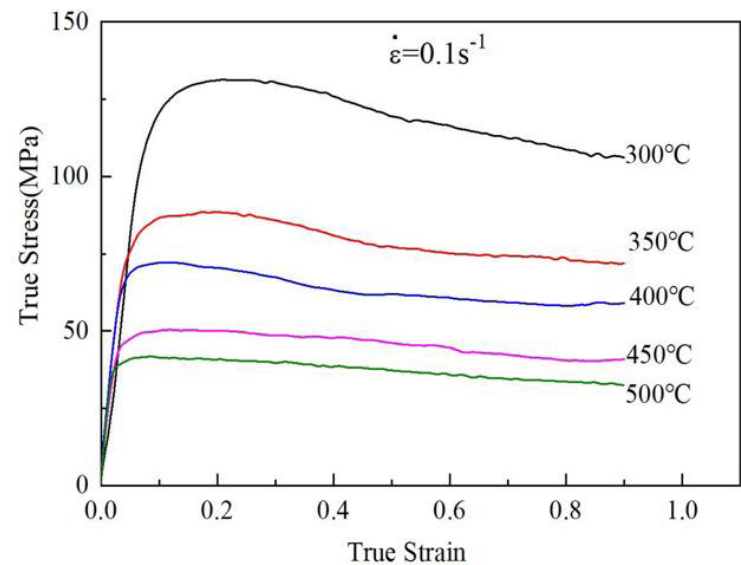

(b)

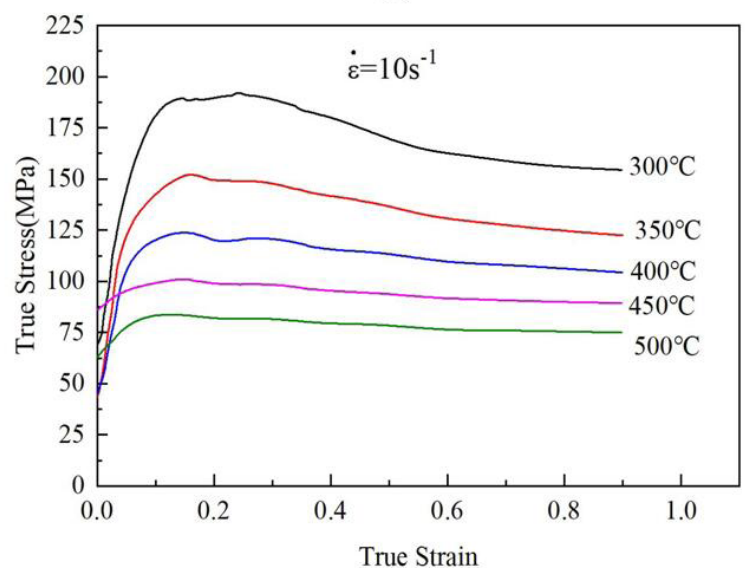

(d)

Figure 2. True stress strain curves of $2219 / \mathrm{TiB}_{2} \mathrm{Al}$-matrix composite

stress at reference condition, $B$ is strain hardening coefficient, $C$ is strain rate hardening coefficient, $n$ is strain hardening exponent and $m$ is temperature softening exponent.

According to Equation 1, it is clear that a reference condition needs to be set before the calculation of this model. In our study, the reference condition was set as the deformation temperature of $300^{\circ} \mathrm{C}$ and strain rate of $0.01 \mathrm{~s}^{-1}$. As shown in Figure 3, at the reference condition, the yielding stress (namely $A$ ) of this composite is about $80 \mathrm{MPa}$.

Under the reference temperature and strain rate, the effect of strain rate and temperature on flow curves could be ignored and Equation 1 can be denoted as:

$$
\sigma=\left(A+B \varepsilon^{n}\right)
$$

Taking natural logarithm of both sides:

$$
\ln (\sigma-A)=\ln B+n \ln \varepsilon
$$

According to Equation 3, it is obvious that $\ln (\sigma-A)$ is linearly relate to lne. Hence, the values of $n$ and $B$ were determined to be -0.8835 and 2.0495 by linear fitting respectively.

Under reference temperature condition, Equation 1 can be denoted as:

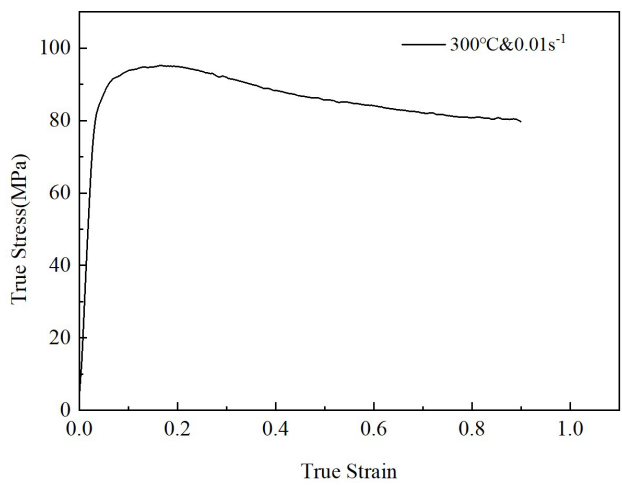

Figure 3. Stress strain curve at reference condition.

$$
\sigma=\left(A+B \varepsilon^{n}\right)\left[1+C \ln \left(\dot{\varepsilon}^{*}\right)\right]
$$

Equation 4 can be converted into:

$$
\frac{\sigma}{\left(A+B \varepsilon^{n}\right)}=1+C \ln \left(\dot{\varepsilon}^{*}\right)
$$

Similarly, $\sigma /\left(\mathrm{A}+\mathrm{B} \varepsilon^{N}\right)$ and $\ln \left(\dot{\varepsilon}^{*}\right)$ is linearly related and $C$-value was determined to be 0.1512 by linear fitting as shown in Figure 4. 


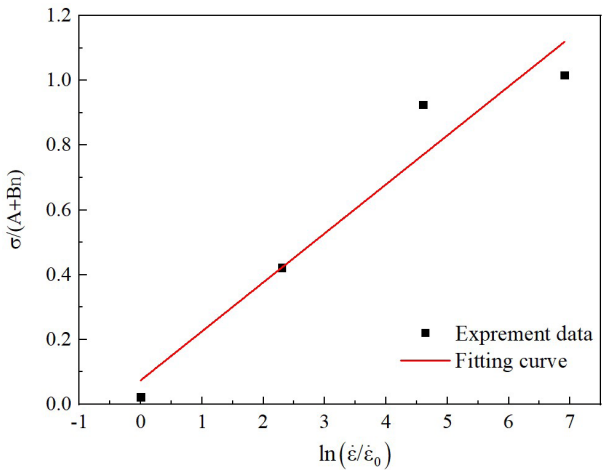

Figure 4. Determination of $C$-value.

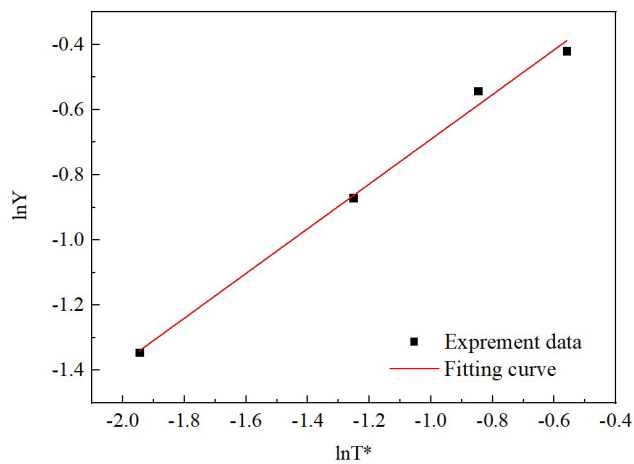

Figure 5. Determination of $m$-value.

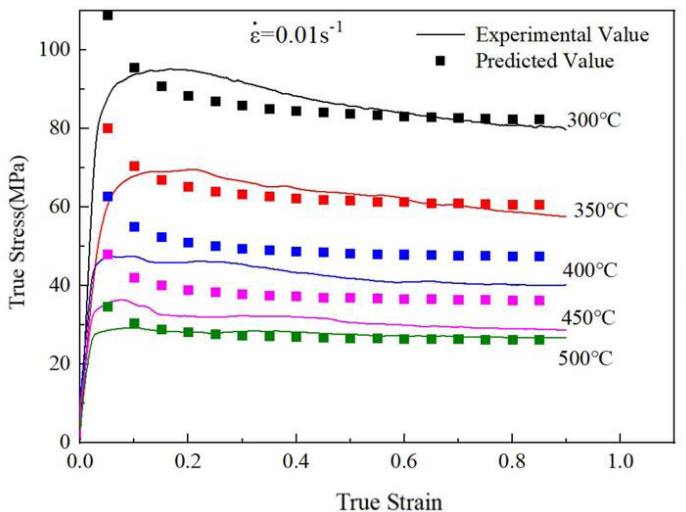

(a)

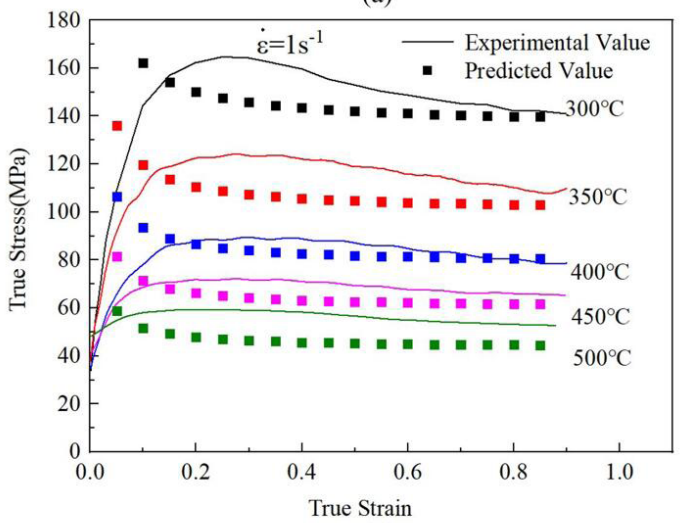

(c)
To obtain the value of $m$, Equation 1 can be expressed as:

$$
1-Y=\left(T^{*}\right)^{m}
$$

Where $Y=\frac{\sigma}{\left(A+B \varepsilon^{n}\right)\left[1+C \ln \dot{\varepsilon}^{*}\right]}$ and $T^{*}=\frac{T-T_{r e f}}{T_{m}-T_{r e f}}$.

Taking natural logarithm of the both sides of Equation 6:

$$
\ln Y=m \ln T^{*}
$$

According to the linear fitting of $\ln Y$ and $\ln T^{*}$ under the strain of 0.3 as shown in Figure 5, the $m$-value was finally determined to be 0.6859 .

Here, after obtaining the material constants, the Johnson-Cook model for $2219 / \mathrm{TiB}_{2}$ Al-matrix composite was constructed as:

$$
\sigma=\left(80+2.0495 \varepsilon^{-0.8835}\right)\left[1+0.1512 \ln \left(\dot{\varepsilon}^{*}\right)\right]\left[1-\left(\frac{T-T_{r e f}}{T_{m}-T_{r e f}}\right)^{0.6859}\right]
$$

Figure 6 shows the comparison between predictions of constructed Johnson-Cook model and experimental results. It can be seen that the predictions are much higher than the experimental results at lower strain condition and close to the experimental results at higher strain condition. Moreover, at lower strain rate condition, e.g. $0.01 \mathrm{~s}^{-1}$ and $0.1 \mathrm{~s}^{-1}$, the prediction accuracy is relative better than that at higher strain rate condition, the error of prediction precision increases with the increasing strain rate.

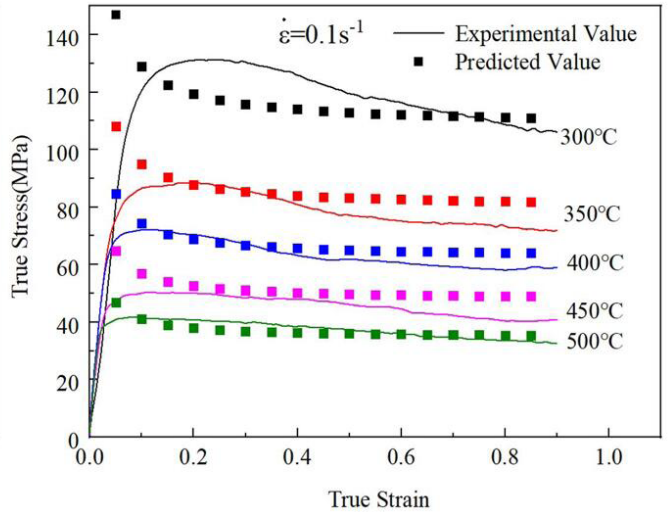

(b)

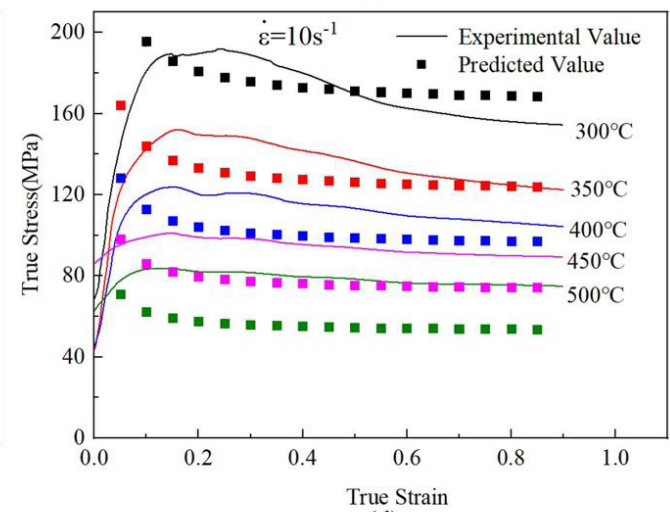

(d)

Figure 6. The comparison between predictions of constructed Johnson-Cook model and experimental results. 


\subsection{Modification of Johnson-Cook model}

As discussed above, the original Johnson-Cook model can describe the flow behavior of $2219 / \mathrm{TiB}_{2} \mathrm{Al}$-matrix composite to some extent, but the prediction precision is not satisfying. The main reasons of lower precision are: 1) according to the original calculation process, linearly fitting $\ln (\sigma-A)$ and $\ln \varepsilon$ will obtain negative $n$-value under low strain conditions, which will result in opposite variation tendency of flow stress and greater error; 2) the accuracy of linear fitting $\sigma /\left(\mathrm{A}+\mathrm{B} \varepsilon^{N}\right)$ and $\ln \left(\dot{\varepsilon}^{*}\right)$ is about 0.91347 which is not high enough. Hence, the slope of this fitted line cannot represent the $C$-value better; 3 ) The precision of predicted flow stress becomes lower with the increasing strain rate, which can be attributed to the $m$-value which is a certain value under different strain rate. Obviously, $m$ should be a function about strain rate.

Due to the larger error of the result of linear fitting $\ln (\sigma-A)$ and $\ln \varepsilon$ as shown in Figure $7 \mathrm{a}$, it is better to choose polynomial fitting. Here, a fifth order polynomial fitting were taken to better fit the relationship between $\ln (\sigma-A)$ and $\ln \varepsilon$. The determination coefficient $\mathrm{R}^{2}$ rises from 0.44949 of linear fitting to 0.99044 . As a result, the following expression was obtained:

$f(\varepsilon)=-2.167-11.940 \ln \varepsilon-13.594(\ln \varepsilon)^{2}-8.294(\ln \varepsilon)^{3}-2.509(\ln \varepsilon)^{4}-0.288(\ln \varepsilon)^{5}$

Where $f(\varepsilon)=\ln (\sigma-A)$.

Similarly, to better fit the relationship between $\sigma /\left(\mathrm{A}+\mathrm{B} \varepsilon^{N}\right)$ and $\ln \left(\dot{\varepsilon}^{*}\right)$, a second order polynomial fitting were taken as shown in Figure $7 \mathrm{~b}$. It can be seen that the $\mathrm{R}^{2}$-value rises from 0.91347 to 0.9379 . At the same time, the following expression was obtained:

$$
\frac{\sigma}{e^{f(\varepsilon)}+A}=1+0.25172 \ln \left(\dot{\varepsilon}^{*}\right)-0.01455 \ln \left(\dot{\varepsilon}^{*}\right)^{2}
$$

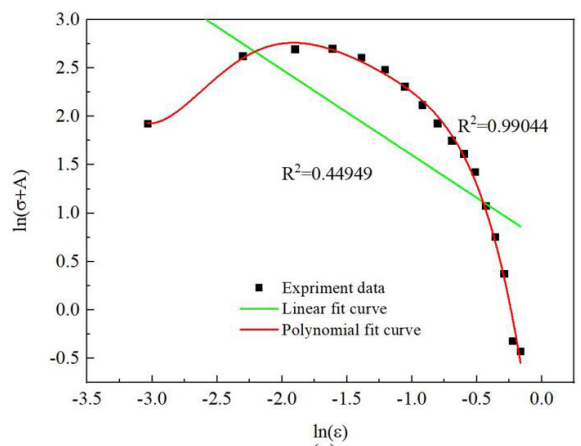

(a)

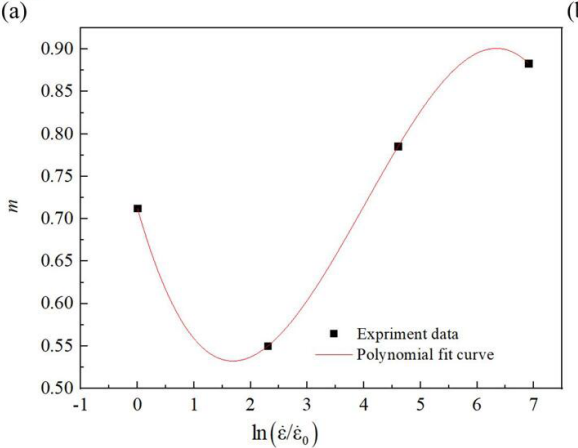

(c)
Moreover, the $m$-values at the strain of 0.3 and different strain rate were calculated. As shown in Figure 7c, the relationship between $m$ and $\ln \left(\dot{\varepsilon}^{*}\right)$ was fitted by a third order polynomial function which is expressed as:

$$
m\left(\dot{\varepsilon}^{*}\right)=0.7125-0.23427 \ln \left(\dot{\varepsilon}^{*}\right)+0.0878 \ln \left(\dot{\varepsilon}^{*}\right)^{2}-0.0073 \ln \left(\dot{\varepsilon}^{*}\right)^{3}
$$

Here, the modified Johnson-Cook model was developed as following:

$\sigma=\left[e^{f(\varepsilon)}+80\right]\left\{1+0.25172 \ln \left(\dot{\varepsilon}^{*}\right)-0.01455\left[\ln \left(\dot{\varepsilon}^{*}\right)\right]^{2}\right\}\left[1-\left(\frac{T-T_{\text {ref }}}{T_{m}-T_{\text {ref }}}\right)^{m\left(\dot{\varepsilon}^{*}\right)}\right]$

where

$f(\varepsilon)=-2.167-11.940(\ln \varepsilon)-13.594(\ln \varepsilon)^{2}-8.294(\ln \varepsilon)^{3}-2.509(\ln \varepsilon)^{4}-0.288(\ln \varepsilon)^{5}$;

$m\left(\dot{\varepsilon}^{*}\right)=0.7125-0.23427 \ln \left(\dot{\varepsilon}^{*}\right)+0.0878\left[\ln \left(\dot{\varepsilon}^{*}\right)\right]^{2}-0.0073\left[\ln \left(\dot{\varepsilon}^{*}\right)\right]^{3}$

\subsection{Prediction precision analysis of the modified model}

Figure 8 shows the comparison between experimental result and predicted result of modified Johnson-Cook model. Compared with Figure 6, it is distinct that the new predicted results are more accurate, especially at low strain conditions. To better analyze the accuracies of the two models, relative coefficient $(R)$ expressed as Equation 13 and absolute average relative error (AARE) expressed as Equation 14 were introduced. As shown in Figure 9, the $R$-value and $A A R E$-value of original Johnson-Cook model are 0.94731 and $10.3747 \%$ respectively and the two indicators of modified model are 0.9852 and $6.4415 \%$ respectively.

$$
R=\frac{\sum_{i=1}^{n}\left(E_{i}-\bar{E}\right)\left(P_{i}-\bar{P}\right)}{\sqrt{\sum_{i=1}^{n}\left(E_{i}-\bar{E}\right)^{2} \sum_{i=1}^{n}\left(P_{i}-\bar{P}\right)^{2}}}
$$

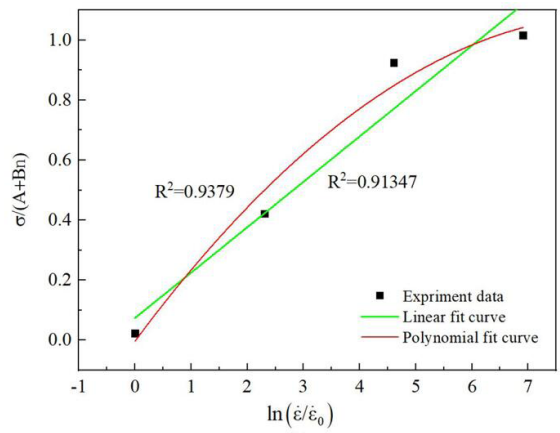

(b)

Figure 7. (a) Fitting error analysis of $n$ and (b) $C$, (c) the fitting curve of $m$. 


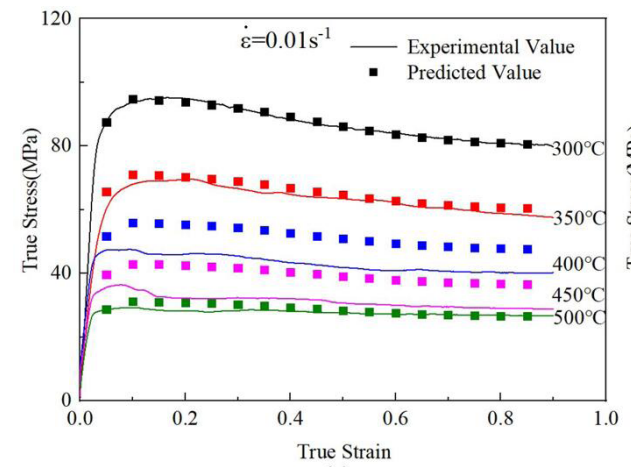

(a)

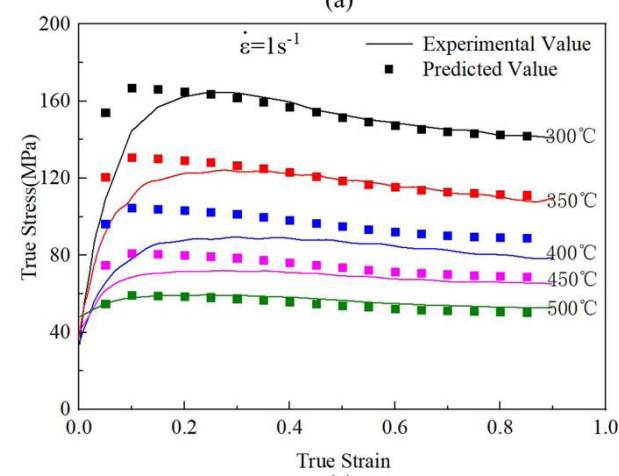

(c)

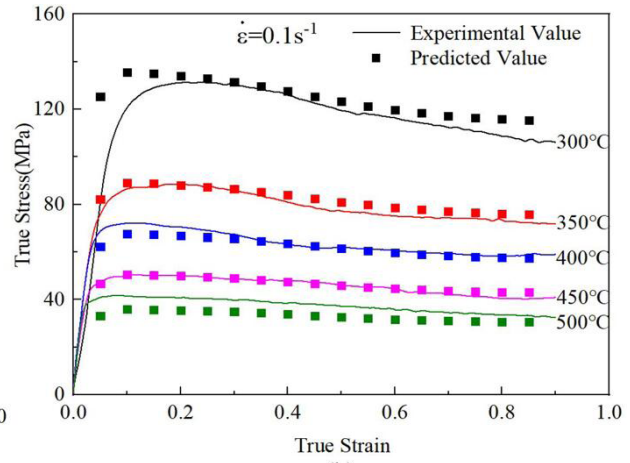

(b)

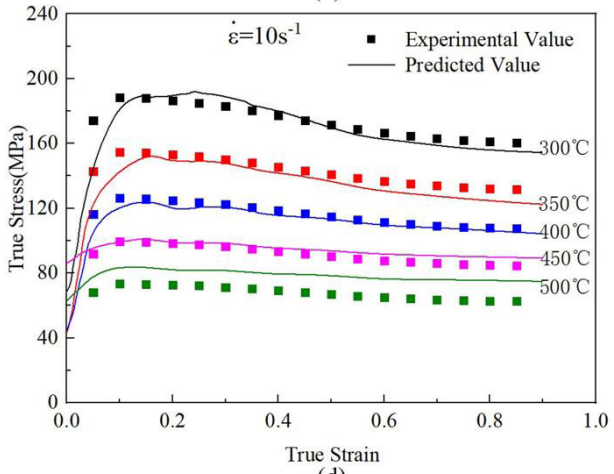

(d)

Figure 8. The comparison between predictions of modified Johnson-Cook model and experimental results.

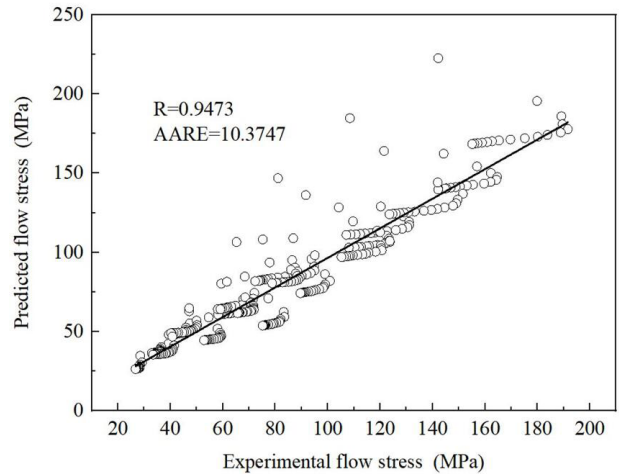

(a)

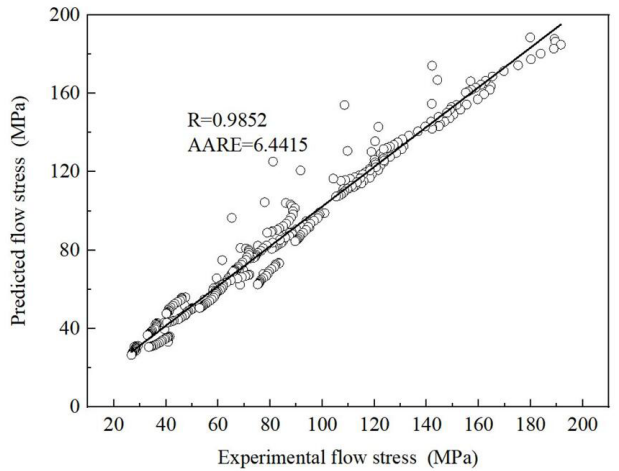

(b)

Figure 9. Error analysis of (a) the original Johnson-Cook model and (b)modified Johnson-Cook model.

$$
A A R E \%=\frac{1}{n} \sum_{i=1}^{n}\left|\frac{E_{i}-P_{i}}{E_{i}}\right| \times 100
$$

where $E_{i}$ and $P_{i}$ are experimental result and predicted result respectively, $\bar{E}$ and $\bar{P}$ are the mean value of experimental results and predicted results respectively.

\subsection{Processing map}

The intrinsic workability of a metal means its maximum ability of deformation without being fractured during hot processing ${ }^{25,26}$. Usually, this ability is characterized by method of processing map which can identify the stable and instable hot working region and help researchers to understand the deformation mechanism and microstructure evolution mechanism of a metal during hot deformation. It is widely accepted that constructing processing maps based on dynamic materials model (DMM) is effective and precise, which was firstly done by Prasad et al. ${ }^{27}$. Prasad et al. ${ }^{27}$ believe that the hot working process is a power dissipation process, the total absorbed power is mainly dissipated by plastic deformation and the structural variation of microstructure during plastic deformation, and this process was denoted as:

$$
P=G+J=\int_{0}^{\dot{\varepsilon}} \sigma d \dot{\varepsilon}+\int_{0}^{\sigma} \dot{\varepsilon} d \sigma
$$

Where $P$ is the total absorbed power, $G$ content represents the absorbed power by plastic deformation and $J$ co-content represents the absorbed power by microstructure evolution. At a giving temperature and strain rate, $J$ co-content can be denoted as ${ }^{21,26}$ : 


$$
J=\int_{0}^{\sigma} \dot{\varepsilon} d \sigma=\frac{m}{m-1} \sigma \dot{\varepsilon}
$$

Where $m$ is strain rate sensitivity index denoted as Equation 17. The value of $m$ can reflect the deformation mechanism of a metal especially the ability of superplastic deformation during hot forming ${ }^{28,29}$.

$$
32 m=\left(\frac{\partial \log \sigma}{\partial \log \dot{\varepsilon}}\right)_{T, \varepsilon} \approx\left(\frac{d \log \sigma}{d \log \dot{\varepsilon}}\right)_{T, \varepsilon}
$$

To calculate the value of $m$, a third order polynomial function can be used to fit the relationship of $\log \dot{\varepsilon}$ and $\log \sigma$ as following ${ }^{30-32}$

$$
\log \sigma=k_{1}+k_{2} \log \dot{\varepsilon}+k_{3}(\log \dot{\varepsilon})^{2}+k_{4}(\log \dot{\varepsilon})^{3}
$$

The $\mathrm{m}$-value can be obtained by taking the derivation of Equation 18:

$$
m=\frac{d \log \sigma}{d \log \dot{\varepsilon}}=k_{2}+2 k_{3} \log \dot{\varepsilon}+3 k_{4}(\log \dot{\varepsilon})^{2}
$$

Where $k_{1 \sim 4}$ are material constants. At a certain strain and deformation temperature, the values of $k_{1 \sim 4}$ can be calculated

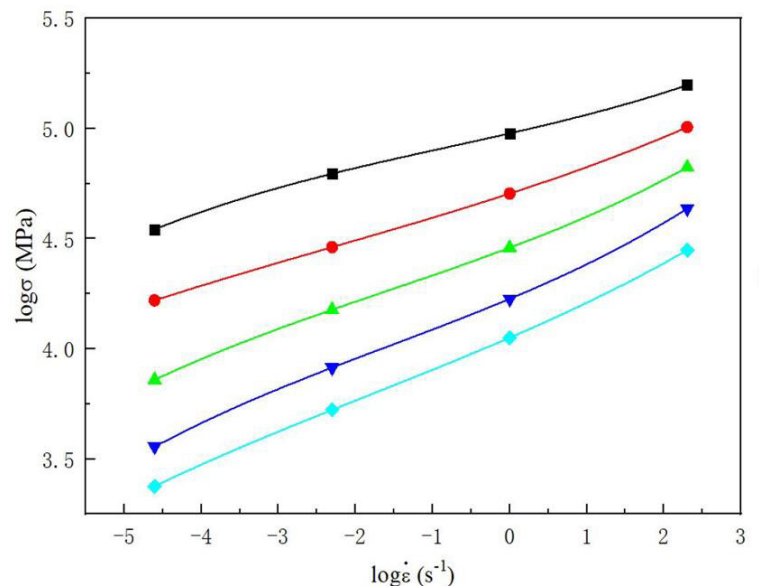

(a) by third order polynomial fitting the relationship of $\log \dot{\varepsilon}$ and $\log \sigma$. For example, Figure 10a shows the fitting relationship of $\log \dot{\varepsilon}$ and $\log \sigma$ under the strain of 0.9 and different temperature conditions. After obtaining the values of $k_{1 \sim 4}$, the $m$-values can be calculated and its 3D response surface map is shown in Figure 10b.

Under ideal linear dissipation condition, $J$ co-content reached its maximum value:

$$
J_{\mathrm{m}}=\frac{\sigma \dot{\varepsilon}}{2}
$$

The power dissipation efficiency $(\eta)$ is expressed as:

$$
\eta=\frac{J}{J_{m}}=\frac{2 m}{m+1}
$$

The value of power dissipation efficiency reveals different deformation mechanism, e.g. dynamic recrystallization (DRX), dynamic recovery (DRV), adiabatic shear band and crack. Generally, higher $\eta$-value reveals higher possibility that DRV and DRX operate. After calculating the $\eta$-values under different conditions, the power dissipation maps at the strain of 0.5 and 0.9 were constructed as shown in Figure 11. The power dissipation maps reflect the workability of this

Figure 10. (a) the fitting relationship of $\log \dot{\varepsilon}$ and $\log \sigma$ under the strain of 0.9; (b) the 3D response surface map of $m$-values.

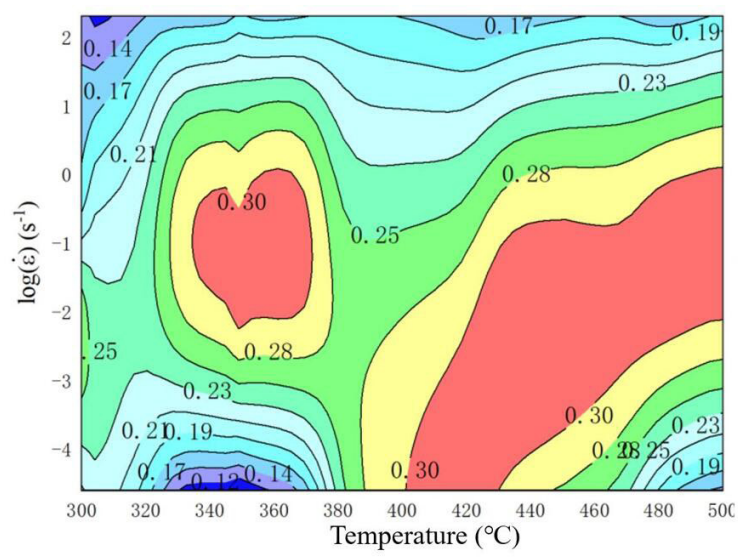

(a)

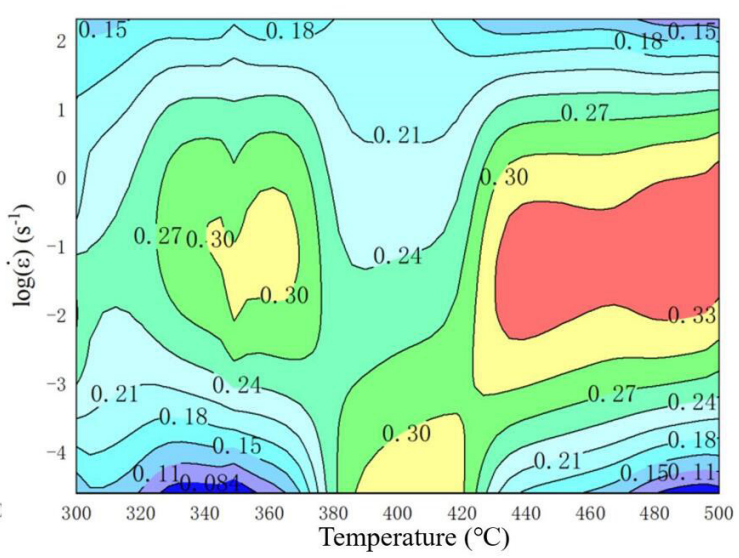

(b)

Figure 11. The power dissipation maps at the strain of (a) 0.5 and (b) 0.9 . 
alloy to some extent by means of $\eta$-values. However, to better understand the working stability of the alloy during hot processing, the instability situations need to be considered and instability criterion needs to be introduced. The common instability criterions for plastic deformation include Gegel's instability criterion ${ }^{33}$, Prasad's instability criterion ${ }^{34}$, Ziegler's instability criterion ${ }^{35}$, Alexzander's instability criterion ${ }^{36}$ and Murty's instability criterion ${ }^{37}$. Here, we choose Prasad's instability criterion which is expressed as ${ }^{27,34}$ :

$$
\xi=\frac{\partial \log \left(\frac{m}{m+1}\right)}{\partial \log (\dot{\varepsilon})}+m<0
$$

Where $\xi$ is the instability coefficient and it indicates the occurrence of instability when it is negative. The instability maps at the strain of 0.5 and 0.9 were constructed as shown in Figure 12 after the determination of $\xi$-values.

By overlapping the instability maps on the power efficiency maps, the processing maps at the strain of 0.5 and 0.9 were obtained as shown in Figure 13. It can be seen that, the $\eta$-values are higher at the conditions of $350^{\circ} \mathrm{C} / 0.1 \mathrm{~s}^{-1}, 450-500^{\circ} \mathrm{C} / 0.1 \mathrm{~s}^{-1}$, $400 \sim 430^{\circ} \mathrm{C} / 0.01 \mathrm{~s}^{-1}$, which reveals that DRX and DRV are more tend to happen. Due to the addition of ceramic particles

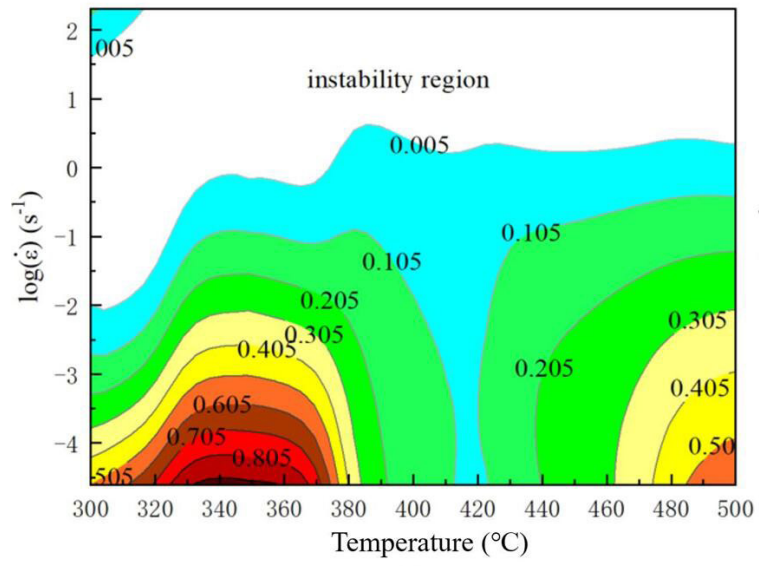

(a)

Figure 12. The instability maps at the strain of (a) 0.5 and (b) 0.9 .

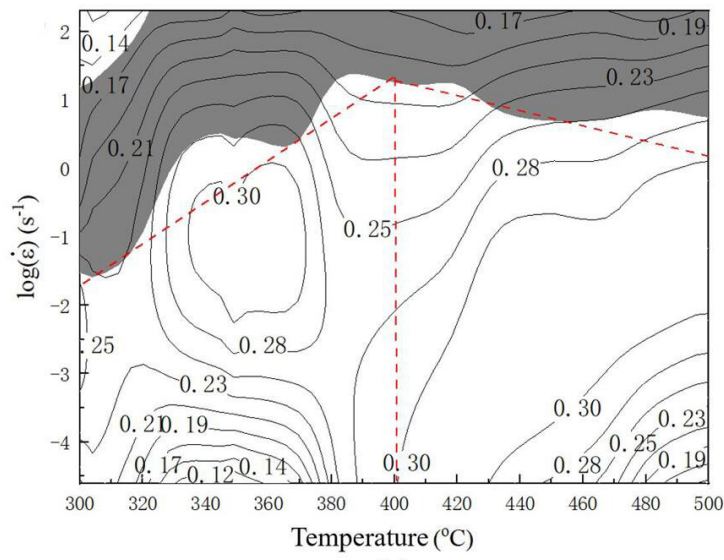

(a) which offer more particles for nucleation, the continuous dynamic recrystallization (CDRX) are more likely to occur. Hence, CDRX operates at this temperature area. Besides, the grey areas in Figure 13 are instability areas which distribute in the regions of high strain rate. As a result, one of the intrinsic optimum workable areas is at the temperature range of $300 \sim 400^{\circ} \mathrm{C}$ and strain rate range of $0.01 \sim 0.1 \mathrm{~s}^{-1}$, another area is at the temperature range of $420 \sim 500^{\circ} \mathrm{C}$ and the strain rate range of $0.01 \sim 1 \mathrm{~s}^{-1}$.

\subsection{Microstructure analysis}

Figure 14a and $14 \mathrm{~b}$ show the microstructures of the deformed center of specimens at the temperature of $350^{\circ} \mathrm{C}$ and strain rates of $0.01 \mathrm{~s}^{-1}$ and $10 \mathrm{~s}^{-1}$, respectively. It is obvious that the flow net in Figure 14a distributed uniformly. As a comparison, a deformation band with an angle of approximately $45^{\circ}$ to the compression axis can be seen in Figure 14b, this structure is usually believed to be shear band which is a typical defect of deformed microstructure. Here, the microstructures coincide with the results of processing map.

Figure 15 shows the microstructures at the temperature ranges of $350 \sim 500^{\circ} \mathrm{C}$ with the strain rate of $1 \mathrm{~s}^{-1}$, it can be seen that $\theta$-phase reduces with the increasing temperature.

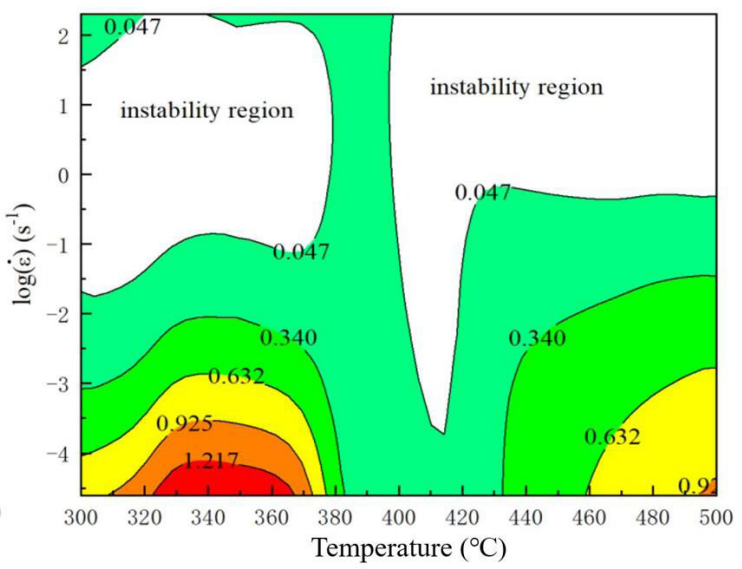

(b)

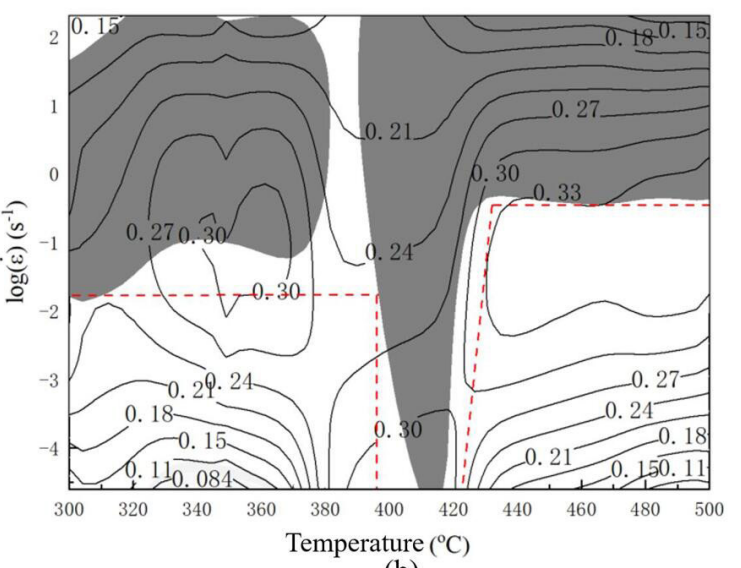

(b)

Figure 13. The processing maps at the strain of (a) 0.5 and (b) 0.9 . 


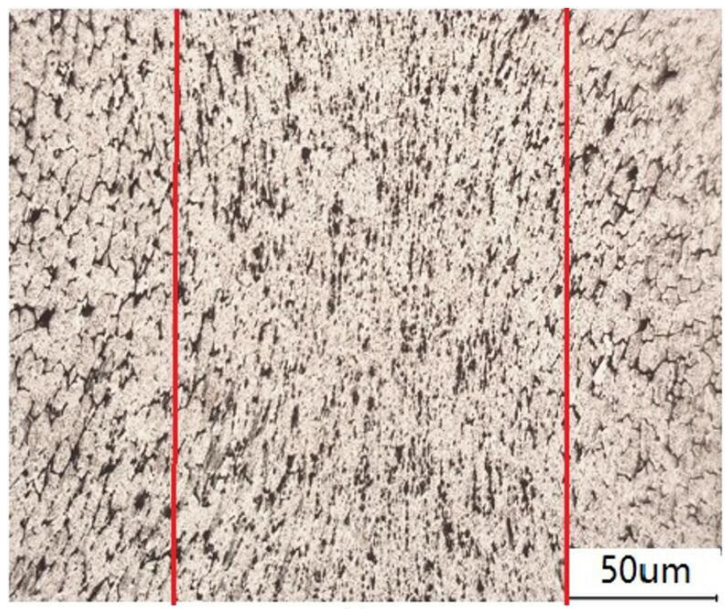

(a)

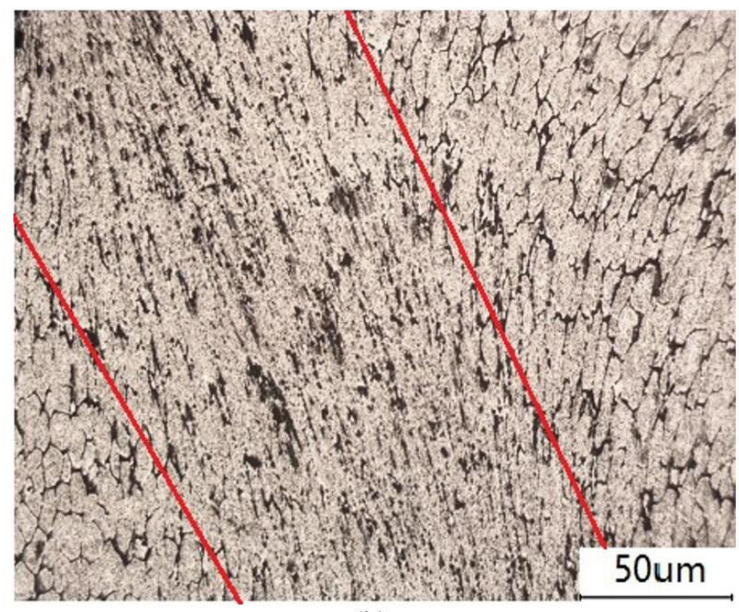

(b)

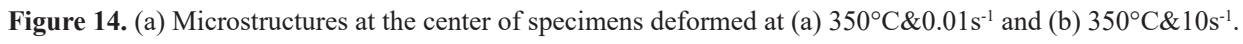

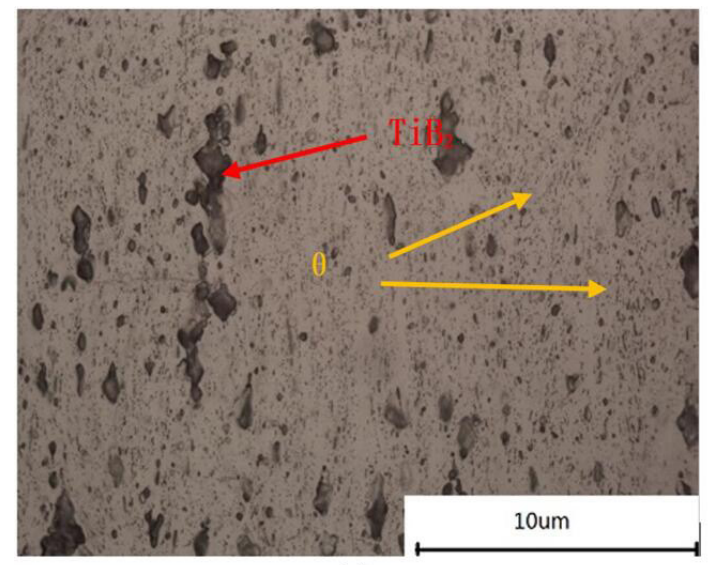

(a)

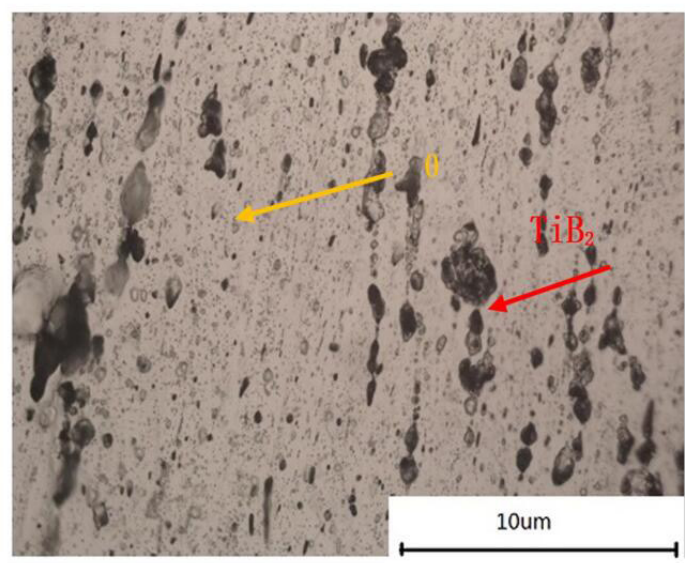

(c)

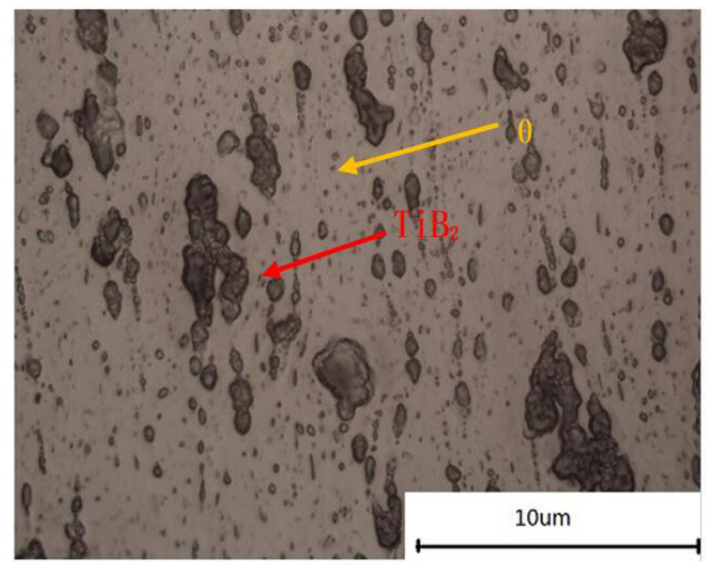

(b)

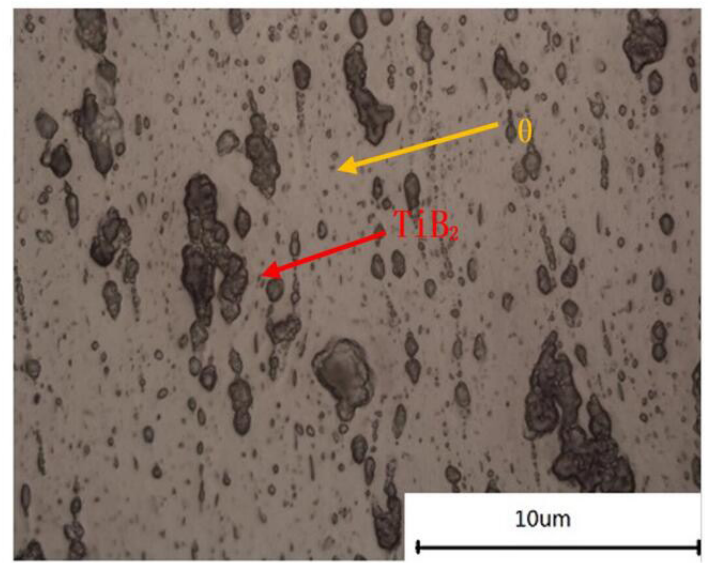

(d)

Figure 15. The microstructures of the specimens at the strain rate of $1 \mathrm{~s}^{-1}$ and different temperatures: (a) $350^{\circ} \mathrm{C}$; (b) $400^{\circ} \mathrm{C}$; (c) $450^{\circ} \mathrm{C}$; (d) $500^{\circ} \mathrm{C}$.

As shown in Figure 15d, $\theta$-phase was vanished at the temperature of $500^{\circ} \mathrm{C}$ because it was dissolved in the $\alpha$-phase matrix, meanwhile, the grain boundary becomes vaguer which coincides with the phase diagram of Al-Cu alloy. Besides, $\mathrm{TiB}_{2}$ particles can also be seen in Figure 15 and they usually concentrated in grain boundary.

\section{Conclusions}

1. The hot deformation behavior of $2219 / \mathrm{TiB}_{2} \mathrm{Al}$-matrix composite was greatly influenced by deformation temperature and strain rate. Also, deformation temperature and strain rate have an interaction effect on flow stress; 
2. A new modified Johnson-Cook model was proposed because the original Johnson-Cook model has greater error after error analysis. As a result, the AARE-value of new model was reduced $37.91 \%$ comparing with original one and the model was denoted as:

$$
\sigma=\left[e^{f(\varepsilon)}+80\right]\left\{1+0.25172 \ln \left(\dot{\varepsilon}^{*}\right)-0.01455\left[\ln \left(\dot{\varepsilon}^{*}\right)\right]^{2}\right\}\left[1-\left(\frac{T-T_{\text {ref }}}{T_{m}-T_{\text {ref }}}\right)^{m\left(\dot{\varepsilon}^{*}\right)}\right]
$$

where

$f(\varepsilon)=-2.167-11.940 \ln \varepsilon-13.594(\ln \varepsilon)^{2}-8.294(\ln \varepsilon)^{3}-2.509(\ln \varepsilon)^{4}-0.288(\ln \varepsilon)^{5}$; $m\left(\dot{\varepsilon}^{*}\right)=0.7125-0.23427 \ln \left(\dot{\varepsilon}^{*}\right)+0.0878\left[\ln \left(\dot{\varepsilon}^{*}\right)\right]^{2}-0.0073\left[\ln \left(\dot{\varepsilon}^{*}\right)\right]^{3}$

3. Processing map at the strain of 0.9 for $2219 / \mathrm{TiB}_{2}$ Al-matrix composite was constructed. There are two stable regions located at the temperature range of $300 \sim 400^{\circ} \mathrm{C}$ with strain rate range of $0.01 \sim 0.1 \mathrm{~s}^{-1}$ and temperature range of $420 \sim 500^{\circ} \mathrm{C}$ with strain rate range of $0.01 \sim 1 \mathrm{~s}^{-1}$.

4. The microstructures are coinciding with the prediction of instability area in processing map. Also, the content of $\theta$-phase reduces with the increasing temperature.

\section{Acknowledgment}

This work was supported by Key projects of technology innovation and application development in Chongqing (cstc2019jscx-fxyd0317), Chongqing Technology and Business University Fund (950318062), Open Research Fund Program of Manufacturing Equipment Mechanism Design and Control Chongqing Key Laboratory of Chongqing (CTBU-KFJJ2019078) and Chongqing basic science and advanced technology research special fund project (cstc2017jcyjAX0175).

\section{References}

1. Jahedi M, Mani B, Shakoorian S, Pourkhorshid E, Hossein Paydar M. Deformation rate effect on the microstructure and mechanical properties of Al-SiCp composites consolidated by hot extrusion. Mater Sci Eng A. 2012;556:23-30. http://dx.doi. org/10.1016/j.msea.2012.06.054.

2. Han Y, Liu X, Bian X. In situ TiB2 particulate reinforced near eutectic Al-Si alloy composites. Compos, Part A Appl Sci Manuf. 2002;33(3):439-44. http://dx.doi.org/10.1016/S1359835X(01)00124-5.

3. David Raja Selvam J, Dinaharan I, Vibin Philip S, Mashinini PM. Microstructure and mechanical characterization of in situ synthesized AA6061/(TiB2+Al2O3) hybrid aluminum matrix composites. J Alloys Compd. 2018;740:529-35. http://dx.doi. org/10.1016/j.jallcom.2018.01.016.

4. Zhu H, Guo G, Cui T, Huang J, Li J, Xie Z. In situ aluminum matrix composites fabricated from $\mathrm{Al}-\mathrm{Ni} 2 \mathrm{O} 3$ system through microwave synthesis. Mater Chem Phys. 2015;153:333-7. http://dx.doi.org/10.1016/j.matchemphys.2015.01.021.

5. Tao R, Zhao YT, Kai XZ, Wang Y, Qian W, Yang YG, et al. The effects of Er addition on the microstructure and properties of an in situ nano ZrB2-reinforced A356.2 composite. J Alloys Compd. 2018;731:200-9. http://dx.doi.org/10.1016/j. jallcom.2017.10.021.
6. Rudra A, Das S, Dasgupta R. Constitutive modeling for hot deformation behavior of Al-5083 + SiC composite. J Mater Eng Perform. 2018;28(1):87-99. http://dx.doi.org/10.1007/ s11665-018-3813-9.

7. Gao Q, Wu SS, Lu SL, Xiong XC, Du R, An P. Effects of ultrasonic vibration treatment on particles distribution of TiB2 particles reinforced aluminum composites. Mater Sci Eng A, Struct Mater Prop Microstruct Process. 2017;680:437-43. http:// dx.doi.org/10.1016/j.msea.2016.10.103.

8. Chen L, Zhao G, Yu J. Hot deformation behavior and constitutive modeling of homogenized 6026 aluminum alloy. Mater Des. 2015;74:25-35. http://dx.doi.org/10.1016/j.matdes.2015.02.024.

9. Hu M, Dong L, Zhang Z, Lei X, Yang R, Sha Y. Correction of flow curves and constitutive modelling of a Ti-6Al-4V alloy. Metals. 2018;8(4):8. http://dx.doi.org/10.3390/met8040256.

10. Lin YC, Chen X-M. A critical review of experimental results and constitutive descriptions for metals and alloys in hot working. Mater Des. 2011;32(4):1733-59. http://dx.doi.org/10.1016/j. matdes.2010.11.048.

11. Johnson GR, Cook WH. A constitutive model and data for metals subjected to large strains, high strain rates and high temperatures. In: Proceedings of the Seventh International Symposium on Ballistics; 1983; The Hague, The Netherlands. Washington: International Ballistics Committee; 1983. p. 541547.

12. Zerilli FJ, Armstrong RW. Dislocation-mechanics-based constitutive relations for material dynamics calculations. J Appl Phys. 1987;61(5):1816-25. http://dx.doi.org/10.1063/1.338024.

13. Lin YC, Chen X-M, Liu G. A modified Johnson-Cook model for tensile behaviors of typical high-strength alloy steel. Mater Sci Eng A. 2010;527(26):6980-6. http://dx.doi.org/10.1016/j. msea.2010.07.061.

14. Long S, Zhou J, Qiu Z-L, Zhou Y-T, Li S-S. A GA-optimized Johnson-Cook model of flow behavior for Ti-6554 alloy in cross-phase temperature range. Mater Res Express. 2019;6(10):6. http://dx.doi.org/10.1088/2053-1591/ab3885.

15. Samantaray D, Mandal S, Bhaduri AK. A comparative study on Johnson Cook, modified Zerilli-Armstrong and Arrhenius-type constitutive models to predict elevated temperature flow behaviour in modified 9Cr-1Mo steel. Comput Mater Sci. 2009;47(2):56876. http://dx.doi.org/10.1016/j.commatsci.2009.09.025.

16. Zhao Y, Sun J, Li J, Yan Y, Wang P. A comparative study on Johnson-Cook and modified Johnson-Cook constitutive material model to predict the dynamic behavior laser additive manufacturing FeCr alloy. J Alloys Compd. 2017;723:179-87. http://dx.doi.org/10.1016/j.jallcom.2017.06.251.

17. He Z, Wang Z, Lin P. A comparative study on arrhenius and johnson-cook constitutive models for high-temperature deformation of Ti2AlNb-based alloys. Metals. 2019;9(2):9. http://dx.doi.org/10.3390/met9020123.

18. Peng X, Su W, Xiao D, Xu G. Investigation on hot workability of homogenized Al-Zn-Mg-Cu alloy based on activation energy and processing map. JOM. 2017;70(6):993-9. http://dx.doi. org/10.1007/s11837-017-2708-9.

19. Sahoo BN, Panigrahi SK. Deformation behavior and processing map development of AZ91 Mg alloy with and without addition of hybrid in-situ TiC+TiB2 reinforcement. J Alloys Compd. 2019;776:865-82. http://dx.doi.org/10.1016/j.jallcom.2018.10.276.

20. Xia YF, Long S, Wang T-Y, Zhao J. A study at the workability of ultra-high strength steel sheet by processing maps on the basis of DMM. High-Temp Mater Process. 2017;36(7):36. http://dx.doi.org/10.1515/htmp-2016-0006.

21. Zeng $\mathrm{S}$, Zhao A, Jiang $\mathrm{H}$, Ren Y. Flow behavior and processing maps of Ti-44.5Al-3.8Nb-1.0Mo-0.3Si-0.1B alloy. J Alloys Compd. 2017;698:786-93. http://dx.doi.org/10.1016/j. jallcom.2016.12.214. 
22. Barnett MR. A practical condition for migration dynamic recrystallization. Acta Mater. 2007;55(9):3271-8. http://dx.doi. org/10.1016/j.actamat.2007.01.026.

23. Huang K, Logé RE. A review of dynamic recrystallization phenomena in metallic materials. Mater Des. 2016;111:548-74. http://dx.doi.org/10.1016/j.matdes.2016.09.012.

24. Sun ZC, Wu HL, Cao J, Yin ZK. Modeling of continuous dynamic recrystallization of $\mathrm{Al}-\mathrm{Zn}-\mathrm{Cu}-\mathrm{Mg}$ alloy during hot deformation based on the internal-state-variable (ISV) method. Int J Plast. 2018;106:73-87. http://dx.doi.org/10.1016/j.ijplas.2018.03.002.

25. Matsumoto H, Naito D, Miyoshi K, Yamanaka K, Chiba A, Yamabe-Mitarai Y. Forging property, processing map, and mesoscale microstructural evolution modeling of a Ti-17 alloy with a lamellar (alpha+beta) starting microstructure. Sci Technol Adv Mater. 2017;18(1):893-904. http://dx.doi.org/10.1080/14 686996.2017.1386530. PMid:29152021.

26. Raj R. Development of a processing map for use in warmforming and hot-forming processes. Metall Trans, A, Phys Metall Mater Sci. 1981;12(6):1089-97. http://dx.doi.org/10.1007/ BF02643490.

27. Prasad YVRK, Gegel HL, Doraivelu SM, Malas JC, Morgan JT, Lark KA, et al. Modeling of dynamic material behavior in hot deformation: forging of Ti-6242. Metall Trans, A, Phys Metall Mater Sci. 1984;15(10):1883-92. http://dx.doi.org/10.1007/ BF02664902.

28. Chiou S-T, Cheng W-C, Lee W-S. Strain rate effects on the mechanical properties of a Fe-Mn-Al alloy under dynamic impact deformations. Mater Sci Eng A. 2005;392(1-2):156-62. http://dx.doi.org/10.1016/j.msea.2004.09.055.

29. Zhan H, Wang G, Kent D, Dargusch M. Constitutive modelling of the flow behaviour of a $\beta$ titanium alloy at high strain rates and elevated temperatures using the Johnson-Cook and modified
Zerilli-Armstrong models. Mater Sci Eng A. 2014;612:71-9. http://dx.doi.org/10.1016/j.msea.2014.06.030.

30. Long S, Xia Y-F, Hu J-C, Zhang J-S, Zhou J, Zhang P, et al. Hot deformation behavior and microstructure evolution of Ti-6Cr-5Mo-5V-4Al alloy during hot compression. Vacuum. 2019;160:171-80. http://dx.doi.org/10.1016/j.vacuum.2018.11.032.

31. Xia Y, Long S, Zhou Y, Zhao J, Wang T-y, Zhou J. Identification for the optimal working parameters of Ti-6Al-4V-0.1 Ru alloy in a wide deformation condition range by processing maps based on DMM. Mater Res. 2016;19(6):1449-60. http://dx.doi. org/10.1590/1980-5373-mr-2016-0448.

32. Long S, Xia Y, Wang P, Zhou Y, Gong-ye F, Zhou J, et al. Constitutive modelling, dynamic globularization behavior and processing map for Ti-6Cr-5Mo-5V-4Al alloy during hot deformation. J Alloys Compd. 2019;796:65-76. http://dx.doi. org/10.1016/j.jallcom.2019.05.031.

33. Gegel HL. Synthesis of atomistics and continuum modelling to describe microstructure. Materials Park: ASM International; 1987.

34. Prasad Y, Seshacharyulu T. Modelling of hot deformation for microstructural control. Int Mater Rev. 1998;43(6):243-58. http://dx.doi.org/10.1179/imr.1998.43.6.243.

35. Ziegler H. Some extremum principles in irreversible thermodynamics, with application to continuum mechanics. New York: John Wiley \& Sons; 1963.

36. Alexander JM. Mapping dynamic material behaviour. Berlin: Springer-Verlag; 1989. http://dx.doi.org/10.1007/978-3-64252515-5_5.

37. Murty SVSN, Rao BN, Kashyap BP. On the hot working characteristics of $2014 \mathrm{Al}-20 \mathrm{vol} \% \mathrm{Al} 2 \mathrm{O} 3$ metal matrix composite. J Mater Process Technol. 2005;166(2):279-85. http://dx.doi. org/10.1016/j.jmatprotec.2004.09.088. 